Gisela Paola Kaczan

Universidad Nacional de Mar del Plata, Argentina

\title{
Alegorías de distinción y presagios de exclusión social en imágenes de mujeres (circa 1920) ${ }^{1}$
}

\begin{abstract}
Resumen: El trabajo aporta una mirada integradora entre los estudios de género y los estudios de la cultura visual. Se busca interpretar las figuraciones de mujeres en revistas ilustradas argentinas de amplia difusión, hacia 1920, para reflexionar sobre las convenciones de las distinciones genéricas, los comportamientos de emulación, las representaciones de exclusión social y las articulaciones que se establecen entre ellos. Se propone que los modos de caracterizar los cuerpos desempeñan un rol crucial; así, la apariencia, la gestualidad y la evocación a un estilo de vida dada por los elementos que componen la escena actúan como fórmulas iconográficas que sustentan la agencia del reconocimiento social. Se presta atención a las condiciones de producción y diseño de los discursos, los temas que se desarrollan, los dispositivos que se utilizan desde los lenguajes y los significados potenciales de reconocimiento. Palabras clave: estudios de género; cultura visual; imágenes corporales femeninas; mecanismos de distinción; sistemas de exclusión.
\end{abstract}

Copyright (๑) 2013 by Revista Estudos Feministas.

'Este trabajo resulta de la reelaboración de un capítulo de la Tesis doctoral Gisela KACZAN: Representaciones de cuerpos femeninos vestidos: Códigos visuales en los mecanismos de producción de exclusión, emulación y distinción social. Mar del Plata 1900-1930. 2011. Doctorado Interuniversitario de Historia, Facultad de Humanidades, Dirección Dra. Dora Barrancos, Co-Dirección Graciela Zuppa Universidad Nacional de Mar del Plata, Mar del Plata.

${ }^{2}$ Cf. Aby WARBURG, 1966; Raymond WILLIAMS, 1982; Clifford GEERTZ,

\section{Introducción}

El recorrido por las producciones imagéticas de la Historia del Arte y de la Cultura advierte que el cuerpo femenino ha sido un territorio inagotable de ficción, de necesidad de verdad y de conjunción del deseo, donde se han proyectado las inquietudes de mujeres y varones desde las formas originarias de su comunicación.

Inicialmente, el conocimiento de estas imágenes devenía de las formas académicas de los historiadores del arte, atentos a la descripción de la obra, la clasificación de los estilos y la detección de los signos. Con el auge de nuevos enfoques para el discernimiento de los hechos culturales ${ }^{2} y$ el desarrollo de las teorías feministas, ${ }^{3}$ estas representaciones 
1987; Jacques LE GOFF, Roger CHARTIER, Jacques REVEL, 1988 ; Giovanni LEVI, 1993; Carlo GINZBURG, 1994; Peter BURKE, 1999; y Raphael SAMUEL, 2000. ${ }^{3}$ Véase Simone DE BEAUVOIR, 1981 [1949]; Judith BUTLER, 1988 Joan SCOTT, 1990; Teresa DE LAURETIS, 1996; Marta LAMAS 1996, 2002; Silvia TUBERT, 2003; y Celia AMOROS, 2005.

${ }^{4}$ Puede remitirse a Rosemary BETTERTON, 1987; Griselda POLLOCK, 1988; Whitney CHADWICK, 1992; Anne HIGONNET, 1993; John BERGER, 2000; y Patricia AYAYO, 2003.

${ }^{5}$ Para ampliar un estado de la cuestión cf. Anna María GUASCH, 2003.

${ }^{6}$ Algunos enfoques vertidos en e contexto argentino se desarrollan en Kathleen NEWMAN, 1990 Leonor ARFUCH, 1996; Dora BARRANCOS e Ricardo CEPPI, 2005: Marcela GENE, 2005; Mirta LOBATO, 2005; Julia ARIZA, 2009. comenzaron a ser consideradas no sólo como ilustraciones, sino como herramientas para acercarse a problemáticas múltiples de la cultura, entre ellas los estudios de género. Las fuentes documentales empleadas tradicionalmente fueron matizadas con la interpretación de pinturas, fotografías e ilustraciones, que permitieron reflexionar acerca de la constitución visual de diversos aspectos de la feminidad y la masculinidad. ${ }^{4}$ Aquí resulta oportuno integrar la perspectiva reciente de los Estudios Visuales o de la Cultura Visual como lugar de convergencia a través de líneas interdisciplinares que pone énfasis en el lado social de la visualidad para explorar el rol de la imagen enclavada en la vida cotidiana sin reducirla exclusivamente a las lecturas canónicas. Así, se examina en los procesos de mirar - ser mirados y en las formas de apreciar el significado, tanto en la dimensión de su producción, cuanto en la de su recepción. ${ }^{5}$

Derivado de estas lecturas, el presente trabajo busca interpretar las figuraciones de mujeres en revistas ilustradas argentinas como vehículos idóneos para reflexionar sobre las convenciones de las distinciones genéricas, los comportamientos de emulación, las representaciones de exclusión social y las articulaciones que se establecen entre ellos. Se propone que los modos de caracterizar los cuerpos desempeñan un rol crucial, así la apariencia, la gestualidad y la evocación a un estilo de vida dada por los elementos que componen la escena actúan como fórmulas iconográficas que sustentan la agencia del reconocimiento social.

Se hace foco en avisos publicitarios de afeites e higiene, hacia la década de 1920. Se han consultado y fotografiado alrededor de 20 ejemplares por año de la revista Caras y Caretas, Buenos Aires - en la totalidad de volúmenes publicados en el lapso de noviembre a marzo- entre las décadas del 1900 al 1930, es decir que se ha indagado un total de 600 ejemplares. Esta información se ha complementado con ejemplares de las revistas El Hogar, Fray Mocho, Plus Ultra y PBT.

Se adhiere a la idea que las imágenes contribuyen a traslucir las coordenadas de los lugares que van habitan-do, las mismas coordenadas que enraízan en las experien-cias de los actores. De allí su interés creciente como medios calificados para emprender los estudios sociales.

\section{Modos de abordaje}

Investigaciones previas sobre estudios de género con imágenes ${ }^{6}$ han dado a conocer, entre otros tantos temas, que los aspectos diversos de lo femenino estaban urdidos por ilusiones referenciales. Es decir, las imágenes modulaban aquello que se suponía de los cuerpos, y codificaban los 
'Laura MALOSETI COSTA, Marcela GENE, 2005.

${ }^{8}$ Gottfried BOEHM, 1994.

${ }^{9}$ Hans-Ulrich GUMBRECHT, 2004.

${ }^{10}$ Nicholas MIRZOEFF, 2003; Keith MOXEY, 2009; Michel MELOT, 2010.

"George DIDI-HUBERMAN, 2005

p. 19.

${ }^{12}$ DIDI-HUBERMAN, 2003, p. 131.

${ }^{13}$ Eliseo VERÓN, 1985, 2004 modos de parecer de las mujeres ligados a los modos de ser femeninos. Al mismo tiempo, esas representaciones tributaban una mirada sesgada porque eran administradas, principalmente, por la mediación de los varones. Así se fue ajustando y conformando un sedimento sígnico que, lejos de ser anodino, indujo constantes en la demarcación de esquemas corporales, morfologías, posturas y disposiciones de ocultamiento-exposición, sostenidas como naturales y modélicas, distantes de lo masculino. No sólo para saciar las expectativas del varón, sino también para provocar la emulación de referencias convenientes por parte de las mujeres mismas, inculcadas en la crianza, y tuteladas a lo largo de la experiencia.

Como se anticipó, la Cultura Visual añade un corpus teórico a estas lecturas. Desarrollada como una visión superadora de las metodologías provenientes de los estudios semiológicos y lingüísticos, ${ }^{7}$ reflexiona acerca del valor de la imagen como metáfora visual de registro, no menos cierta que las secuencias ordenadas y lineales de las palabras. ${ }^{8}$ Proporciona la capacidad de asistir al nivel de los significados- relaciones significantes, de un modo más inclusivo al que podrían hacerlo sólo los textos. Se trata de entender que las propiedades físicas de las imágenes son tan importantes como su repercusión en lo social, y que se debe estar en sintonía con los "efectos de la presencia", cuanto con los "efectos del significado."

Al mismo tiempo, plantea la revisión de las variables de "representación", apostando por el status de la imagen como "presentación". Si la "representación" concibe que la imagen tiene un significado precedente al acto de reconocimiento por parte del observador, la "presentación" añade una dimensión relativizadora, porque incorpora la idea de un principio dinámico: la imagen es capaz de generar su propio significado en la yuxtaposición con su contexto. Se propone que en el transcurso del tiempo, y según la posición subjetiva de quien la elucide, se inauguran nuevas formas de valor, de evocación y de sentido. ${ }^{10}$ Se sugiere que en la imagen hay "un montaje de tiempos heterogéneos,"1 porque se condensan el momento de su gesta y de los instantes sucesivos de cada contemplación: "todos los tiempos se encuentran uno con otro, chocan, o se basan plásticamente uno en el otro, se bifurcan, o incluso se enredan unos con otros." ${ }^{2}$ Es el observador quien tiene la clave para re-estimular, re-interpretar, re-criticar el destino en tránsito de lo figurado.

Con el fin de rastrear estas cuestiones en las imágenes de revistas ilustradas, resulta operativa la teoría de los discursos sociales desarrollada por Eliseo Verón, y la noción de contrato de lectura. ${ }^{13}$ En consecuencia, se contemplan las condiciones de producción y diseño, aquellas que orientan la generación 
14 Joan COSTA, Abraham MOLES, 2005, p. 73.

${ }^{15}$ Erving GOFFMAN, 1988. de un discurso, los temas que se desarrollan, los dispositivos que se utilizan desde el lenguaje, y las condiciones potenciales de reconocimiento, asociadas a los alcances de lectura del mensaje. Esta manera de desentrañar las manifestaciones visuales enriquece el análisis, porque los mensajes en la prensa resultaban ser una estrategia efectiva para socializar facetas de las representaciones dominantes.

\section{El cuerpo representado}

Con el desarrollo de las revistas ilustradas en el contexto argentino hacia 1900, el cuerpo femenino en imágenes se volvió cada vez más omnipresente y adquirió un espacio de influencia pública para su exposición. Los avisos publicitarios fueron uno de los soportes, y a medida que se diversificaban las marcas no sólo se daban a conocer las tendencias en el vestir y el repertorio de artículos para la higiene y la estética, sino que también se difundían proyectos corporales.

Era usual que se combinaran campos de mensaje verbal y de mensaje icónico. El primero, daba las explicaciones por ser la forma de la argumentación y del discurso; el segundo, mostraba y demostraba por ser la forma de representación. ${ }^{14}$ El texto, en general, terminaba de completar el enfoque de la imagen y datos específicos como las propiedades, componentes y modos de uso de las mercancías, el nombre del fabricante y distribuidor. La imagen jugaba con otras ventajas: al impactar rápidamente en el receptor por su atractivo visual, resultaba de fácil lectura y significativa. Podía captar la atención de quien la observara y podía, también, transferir una carga emocional para conmover. Los productores de mensajes se valieron de su poder persuasivo, y durante los inicios del siglo XX la ilustración fue una de las técnicas ampliamente utilizadas.

En esta modalidad se consiente la existencia de una dimensión ilusoria que no tiene que ver estrictamente con los parámetros de lo cotidiano tal cual es. Se habilita la implementación de recursos plásticos que traducen "realidades perfeccionadas" 15 , y se programan escenas que fortalezcan la identidad del producto, lo que el cuerpo institucional pergeñaba como modelo-usuaria para impulsar la compra. El dibujante se desliga del uso de personificaciones de carne y hueso, como podrían ser las figuras presentes en una fotografía, e invierte en fantasías que condensan las expectativas del anunciante.

Las protagonistas concentraban gran parte del atractivo, lucían momentos de contemplación, entretenimiento o disfrute, y un estilo de vida aventajado. Sus cuerpos no aludían a identidades individuales, sino a cuerpos sociales, es decir que "el cuerpo aparece en el espejo de lo social 

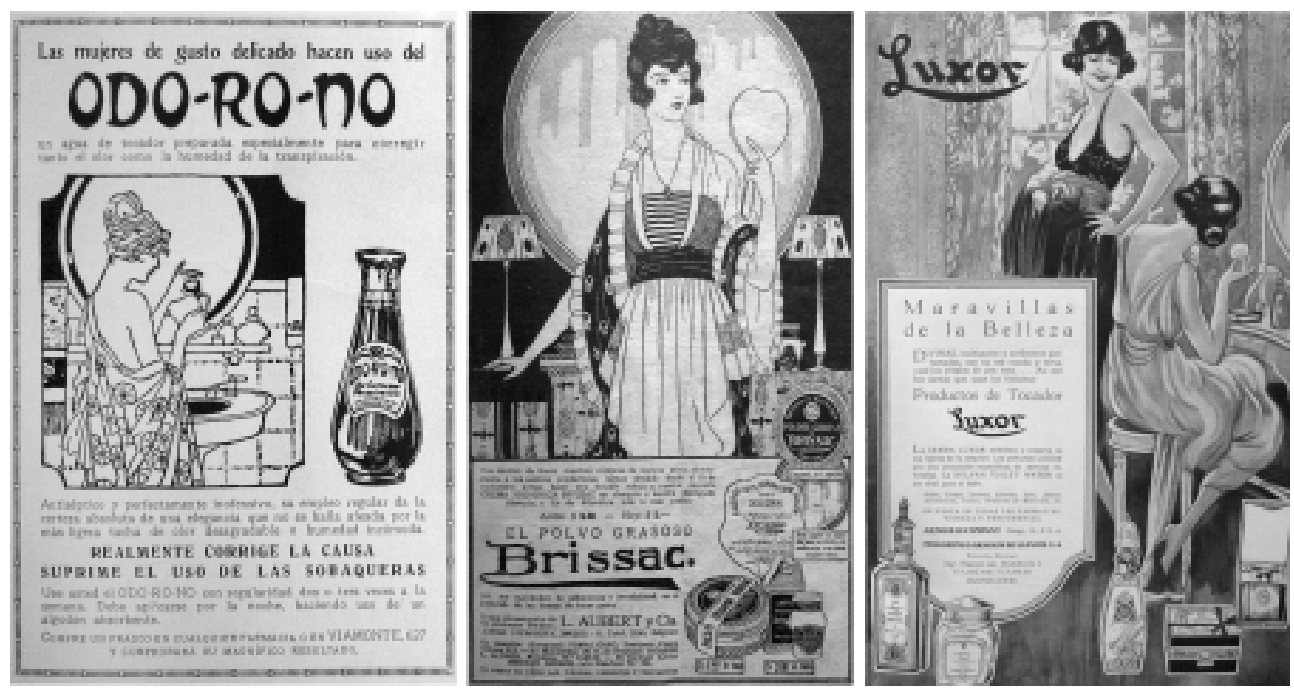

Imagen 1: Plus Ultra, mar. 1923. Caras y Caretas, nov. 1924. Plus Ultra, dic. 1921.

${ }^{16}$ David LE BRETON, 2002, p. 81.

como objeto concreto de investidura colectiva, como soporte de las escenificaciones y de las semiotizaciones," ${ }^{16}$ devienen en artilugios para difundir actuaciones con impacto extensivo. Son jóvenes, bonitas, delgadas, con el cabello arreglado, y bien vestidas. En relación con esto último, se advierte que las tipologías indumentarias no siempre tienen el fin de operar como expresiones de una moda corriente, la búsqueda está orientada a ostentar el aspecto admirable del cuerpo como resultado de los productos empleados. Polvos, cremas, lociones, jabones, talcos, actúan sobre la piel, por lo tanto, es lo que se exhibe, y prevalecen las prendas de lencería, o los vestidos escotados.

Con respecto al lenguaje corporal, las posturas respondían a un inventario de transiciones para interpretar roles animados por parte de la modelo. Se aseguraban inclinaciones y escorzos gráciles y, en ocasiones, se aventuraban matices de seducción. Del mismo modo, las torneadas extremidades conformaban destrezas pre-moldeadas, se exageraban los rasgos de sutileza, sobre todo en los dedos de las manos y en el arqueado de los pies, como si quisiera codificarse desde lo gestual el encanto y la subjetividad femenina. ${ }^{17}$ Al respecto, en la prensa contemporánea se publicó: "los pies hablan a su modo y cuando se consigue aprender su lenguaje, se dispone de una clave preciosa para descifrar uno de los grandes misterios del mundo: el pensamiento de la mujer [...]". ${ }^{18}$ Este discurso advierte sobre la curiosidad que despertaba la comunicación no verbal como una alternativa que favorecía el conocimiento de los 
${ }^{20}$ Para ampliar véase George VIGARELLO, 2007; Denise JODELET, 2007. otros, en especial el develo de la personalidad femenina, situación que parece ser activada por los ilustradores.

¿Qué sucede con los rostros? Si en él se hallan los estímulos típicos del individuo y los instantes en que se coagulan los procesos anímicos, ${ }^{19}$ el profesional concibe mímicas faciales con el fin de comunicar situaciones de expectativa, atención y sentimientos de complacencia. La sonrisa, en general, distaba de ser estridente, no se presentaban muecas desvergonzadas, más bien rictus de labios entreabiertos con discreción. Este modelo, como forma de mantener un semblante de mesura, conciliaba con una mujer decente $y$ apoyaba la estabilización de un estereotipo conveniente.

Los argumentos dejaban en claro que la apariencia bella garantizaba la distinción, y que era sólo para algunas elegidas. Es así que no se podía sino enfatizar en la caracterización de mujeres pertenecientes a clases altas debido a su poderosa vinculación con la idea de "carrousel de vanidades." Es congruente la inclusión frecuente del sustantivo "damas", así como "damas de buen gusto" o "damas de nuestro gran mundo" en referencia a las futuras usuarias. Sin ambigüedades, se apelaba al carácter superior de los artículos desde las adjetivaciones que conformaban el cuerpo de textos: "los perfumes de la nobleza", "los productos más finos y exquisitos", "perfumes aristocráticos". Lo "aristocrático" fue considerado como sinónimo de lo refinado, vinculado con las modalidades de consumo suntuario más que con el origen social. No es que las protagonistas testimoniaran un origen noble, se trataba de hacerlas partícipes de una dimensión simbólica, como una forma de halagarlas.

Otro aspecto elocuente de los avisos ha sido el entorno dibujado: el cuarto de baño y el de toilettes aparecen periódicamente para acoger la ceremonia secular. Se trata de espacios dentro de la vivienda en los que la mujer garantizaba un ámbito para sí misma, para tomarse el tiempo de estudiarse y mutar su imagen, de entregarse al "culto de la belleza." 20

Es frecuente que en el sitio apareciera un artefacto personal con el cual numerosos rostros publicitarios dialogaban: el espejo. El espejo restituye la imagen del cuerpo propio y asume las posibilidades de la mirada ajena, entonces, es un aliado decisivo en el conocimiento de la fisonomía personal y en su corrección. Espejos de mano, espejos de pie, espejos en tocadores pueblan los avisos y anuncian su mediación para satisfacer las expectativas-vigilancias personales y las del mundo exterior. Vale recordar que hacia los años que focaliza este estudio, no estaba generalizada la propiedad de un cuarto de baño interior con el confort y equipamiento moderno, mucho menos un cuarto de toilettes. En este sentido, en revistas ilustradas, como en El Hogar de

1044 Estudos Feministas, Florianópolis, 21 (3): 1039-1058, setembro-dezembro/2013 
${ }^{21}$ El Hogar, jul. 1923.

${ }^{22}$ Baronne STAFFE, 1899, p. 4.

${ }^{23}$ Cf. SIMMEL, 2007

${ }^{24}$ La Esfera, 1914.

25 ROBIN, 1919 citado por Dora BARRANCOS, 1990, p. 271.
1923, se publicaban artículos con opciones ingeniosas para instalar "gabinetitos prácticos y elegantes en las casas antiguas". ${ }^{21}$ En manuales de cuidado femenino se explica que era "el lugar de la revelación", donde las mujeres luchaban por el "armamento de su vanidad", por la felicidad y contra las dificultades de la vida, los estragos del tiempo y los defectos $\mathrm{O}$, al menos, los mitigaban. Era un santuario al cual nadie debiera ingresar, mucho menos el esposo, por un "exquisito sentido de decencia y por un instinto de coquetería bien entendido." ${ }^{22}$ George Simmel reflexiona sobre la noción de coquetería para explicar las relaciones de posesión genérica. Señala que en la acción de adornar el cuerpo se encubren y se ocultan estímulos de carácter sexual, en una simultánea "oferta y negativa" y, al hacerlo, se atrae la atención sobre ciertas partes, sobre los encantos, y se oscila en la simultaneidad del sí y del no, es decir, la simultaneidad de la posesión y la no posesión que es, también, la fórmula del erotismo. ${ }^{23}$ En la revista La Esfera de Madrid, una cronista de moda exclama a favor del contrato omiso entre la mujer y la coquetería:

Nada más lógico, más natural, ni más necesario que la mujer procure adornarse, excitar la curiosidad y la admiración de las gentes. [...] La coquetería, en su acepción más amplia y honrada, es un arma poderosa, irresistible, que debe esgrimir la mujer en todas las circunstancias sin rebasar nunca los permitidos linderos. iYo, mujer, bendigo al mágico, al subyugador, al soberano poder de la coquetería! ${ }^{24}$

Es claro que las imágenes se respaldaban en discursos de este tipo para traducir mandamientos acreditados al género.

Pero, como es lógico, la aceptación no era unívoca. Se adjunta un fragmento escrito sobre las prédicas que los detractores de los grupos burgueses, como los anarquistas y socialistas, hacían a este tipo de representación:

Esclava durante mucho tiempo conserva las costumbres de esclava [...] Como a los salvajes, les gustan las cosas doradas, las pedrerías [...] gusta de las pinturas corporales, pinta sus ojos, sus labios, sus mejillas; como los salvajes se deforma y se mutila [...] en los cerebros que están deprimidos por la esclavitud, la vanidad es más fuerte que todo. Es necesario que se niegue a ser una vez más una muñeca, otra vez una sirvienta y siempre una propiedad..$^{25}$

La cita de Paul Robin, perteneciente a la obra La esclava, difundida en el contexto anarquista argentino, habla por sí misma sobre el uso de ornatos y afeites como una afrenta a la autonomía de la mujer. En particular, alude a las pretensio- 
nes de dispendio propias de la high, y sugiere condiciones estereotipadas en situaciones de frivolidad y presunción, como si se tratara de virtudes - con sarcasmo - que debían adoptarse en estos grupos, para reproducir lineamientos en las asimetrías sociales.

\section{Tácticas de exclusión social}

Una estrategia dilatadamente empleada para remarcar las desigualdades en los avisos vinculados al embellecimiento, sin ser exclusiva de este tipo, fue la relación patronacriada. Las imágenes pueden analizarse desde diferentes aristas, pero es incuestionable el enlace con las formas de exclusión social y con los contrastes de modelos femeninos concernientes a la posición, a la capacidad de acceder al arreglo personal, incluso a las asociaciones con la dignidad.
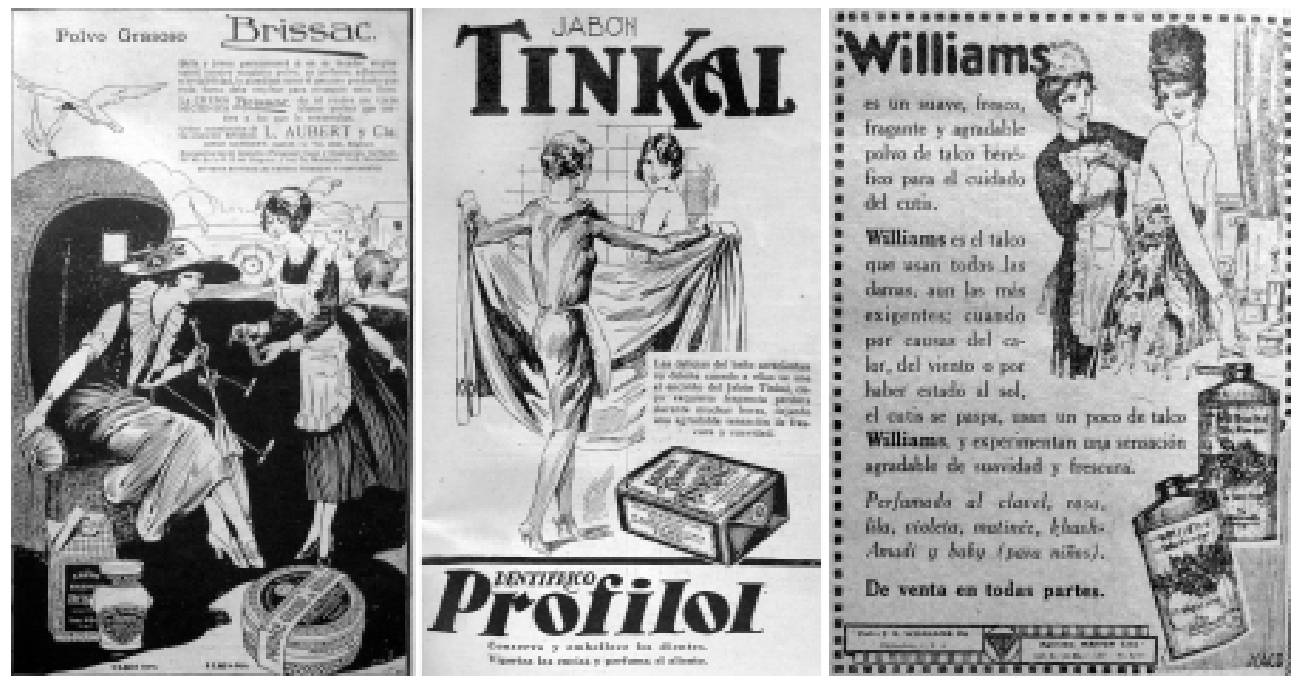

Imagen 2: Caras y Caretas, ene. 1920. Caras y Caretas, octubre, 1929. El Hogar, octubre 1921.

La relación de subordinación es directa: una mujer oficiaba de empleadora, y otra de empleada. La primera encarnaba un rol afín al discurso de la domesticidad. La estadía en el ámbito de la vivienda se acoplaba al mandato de la división sexual del trabajo y sugería cierto bienestar económico que, entre otras cosas, brindaba oportunidades para el arreglo personal. Asimismo, permitía disponer de servicio doméstico para resolver las tareas cotidianas del planchado, lavado, cocina, costura y cuidado de los niños. 
${ }^{26}$ Thorstein VEBLEN, 2005 [1899].

${ }^{27}$ Para un panorama de las líneas de investigación en el contexto argentino se referencia Graciela QUEIROLO, 2006

${ }^{28}$ Caras y Caretas, oct. 1921.

${ }^{29}$ Marcela NARI, 1998; SCOTT, 1993.

${ }^{30}$ Caras y Caretas, 1921.
Al estudiar estas prácticas durante los primeros años del siglo XX, Thorstein Veblen esgrime que el tener demasiados deberes sociales impide hacer aquello que requiere esfuerzo; por lo tanto, el tiempo con el que se cuenta debe emplearse en tareas vinculadas con la "ociosidad notoria," 26 como los paseos, las visitas, la concurrencia a los salones de moda o las actividades de "hermosearse".

Las mujeres de sectores más humildes cubrían los menesteres inconvenientes. Incorporadas al mercado del trabajo asalariado, no respondían en primera instancia al propósito de superación o realización personal, como podía ser el de educadoras, administrativas o empleadas de comercio; sus móviles, en mayor medida, tenían que ver con las carencias económicas de la familia y con la búsqueda de ingresos complementarios a los que aportaban los varones: ${ }^{27}$ "al salir del convento, cumplidos los 18 años quiere ser dactilógrafa o bien vendedora o aspira a cualquier otro empleo, pero a criada ijamás!" ${ }^{28}$ Si bien no dejaba de ser considerado un trabajo femenino, ya que las actividades expresaban la "tendencia natural" vinculada al cuidado del hogar y a las tareas maternales, tenía un reconocimiento social exiguo. ${ }^{29}$ En particular, las llamadas sirvientas ocupaban el primer nivel en la escala del trabajo femenino. Esto significa que el acceso a los puestos no requería capacitación formal o informal, y carecían de experiencias laborales previas. La situación contribuía con una posición de negociación poco favorable de las condiciones laborales y de la remuneración de los ingresos. A esto se asociaba, en ocasiones, el sufrimiento de diferentes prejuicios vinculados con la contracción de enfermedades, sospechas de una moral licenciosa, la incompatibilidad con las funciones de la maternidad, o el inconveniente de perder rasgos de feminidad. Como contrapartida, se debe considerar que el trabajo doméstico podía ofrecer situaciones gratificantes, dado que la contigüidad con la familia propiciaba cierta vinculación emocional, la creación de lazos de confianza y afecto mutuo de un modo particular, diferente al que podría experimentarse en un ámbito extrahogareño.

¿De qué maneras se resignifican estas cuestiones en el plano ilustrado? Los avisos no ahondan en los aspectos negativos o incómodos, más bien simbolizan interacciones armoniosas entre la empleada y su empleadora quien, patentemente, es la usuaria de los productos ofrecidos. Se vislumbra un vínculo "cimentado por la fidelidad y devoción de una parte y la protección y relativa intimidad de la otra que acababan por convertir con frecuencia el plazo del servicio estipulado en un contrato vitalicio," tal como se menciona en un artículo de la revista El Hogar en tono de ironía. ${ }^{30}$ No hay lugar al conflicto o la tensión aunque en otros artículos de la 
${ }^{31}$ Caras y Caretas, 1921.

${ }^{32} P B T$, ene. 1905.

${ }^{33}$ VEBLEN, 2005 [1899], p. 73. prensa se revelen opiniones encontradas de las "señoras" y de las "oprimidas", y se postule que "la dueña de casa [...] no encuentra sivienta competente y mucho menos respetuosa. Y sucede, entonces, que [...] es la guerra declarada entre patrona y sirvienta, con la secuela obligada de disgustos y molestias" 31 , o que "el ideal emancipador de los domésticos está, como el nombre lo dice, en domesticar a los patrones que son fieras bravas." 32

Las imágenes retratan la asistencia de muchachas durante momentos de privacidad con la señora y, en este aspecto, "la presencia de los servidores domésticos y, sobre todo, de la clase especial de servidores personales, es una concesión que hace la comodidad física a la necesidad del decoro pecuniario." 33 Es decir, como el trabajo que se debiera realizar en lo cotidiano es demasiado arduo, se hace necesaria la colaboración de otras personas para realizar los cometidos de índole personal. De acuerdo con esto, se insiste en mostrar la condición de favores de la empleada: ayuda a vestirse, alcanza los artículos, encrema el cuerpo, y se cubren con solvencia las expectativas de ejercer una posición aventajada.

Las desigualdades también se hacen ostensibles en el modo de vestir. La indumentaria del servicio doméstico denuncia su función laboral y se adscribe a un código formal riguroso. Con características predeterminadas, sobre el traje de color oscuro se adicionan accesorios que no permiten exteriorizar las preferencias. Vestir un uniforme ya es una expresión de subordinación, es un signo de reconocimiento, clasificación y exclusión. Por un lado, porque sitúa al usuario dentro de pertenencias sociales y remite a la imagen de un grupo. Por otro, porque instaura proxémicas particulares entre la empleada y su empleadora que se derivan de la labor y, además, porque mientras que la patrona tiene derecho a ostentar sofisticadas y renovadas apariencias, la empleada se mantiene austera e invariable. Algunos avisos sugieren el contexto de la playa, y esto también apuntala ciertas concesiones, porque eran los grupos de elite los que podían trasladar al personal de servicio al lugar de veraneo para que acudieran, también allí, a sus demandas.

No se puede pasar por alto que la caracterización de las empleadas estaba rectificada. Si bien se presentan excepciones, en su mayoría, y como se marcó, provenían de sectores bajos -migrantes del interior o extranjeras, pupilas de conventos y asilos - por lo que no era habitual que su aspecto físico exteriorizara una esmerada asistencia. Asimismo, comparten una escasa valoración del significado social que proporciona el talante como otra de las vías para acceder a beneficios reales y simbólicos. ${ }^{34}$ Reflexionando con Mirta Lobato, así como se plantea una tensión entre honra y 
${ }^{35}$ LOBATO, 2007.

deshonra, entre trabajo y virtud, hay una oposición entre trabajo y belleza, dado que en el imaginario social la mujer que trabaja no puede ser bella. ${ }^{35}$ En los avisos se vislumbran muchachas arregladas, con rostros y movimientos delicados, fisonomías que concuerdan con los atributos distintivos de las empleadoras. Nuevamente, se apela a seducir la atención de la lectora planteando situaciones agradables. Lo que se custodia es la diferencia de roles en varias oportunidades, la postura del cuerpo revalida la inclinación de quien obedece sin mirar a quien sirve.

En conexión con este tema, merece la atención una serie de viñetas de entretenimiento infantil. El juego consiste en recortar las prendas dibujadas y vestir al personaje de cuerpo entero.
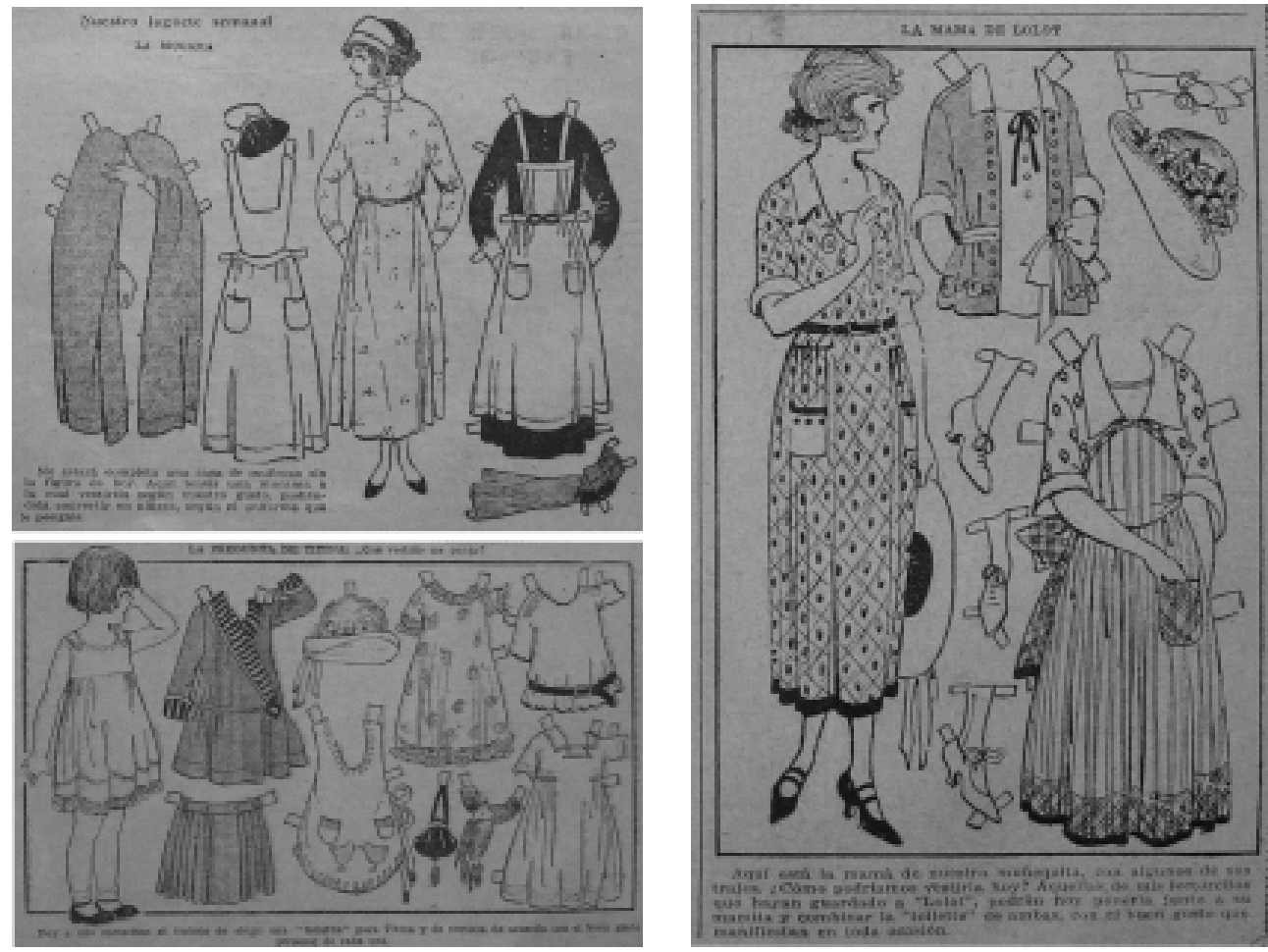

Imagen 3: El Hogar, ago. 1923. El Hogar, mar. 1923. El Hogar, ene. de 1923.

Se ha empleado un juego para comunicar deliberadamente esquemas sociales. En el plano bidimensional se clasifican a personajes que son sólo dibujos; sin embargo, los mismos criterios pueden ser transferidos a personas de la 
${ }^{36}$ El Hogar, ago. 1923.

${ }^{37}$ El Hogar, ene. 1923. vida real. La indumentaria, más o menos diversificada, es clave por conformar las piezas del entretenimiento y por el poder taxativo que tiene en la comunicación de roles y en la manifestación de códigos de distinción de inmediato reconocimiento. La variación para la doméstica se asocia al tipo de labor, "aquí tenéis una mucama a la cual vestiréis según vuestro gusto, pudiéndola convertir en niñera, según el uniforme que le pongáis." 36 En cambio, para las otras protagonistas la elección se hace por una cuestión de estética: "¿Cómo podríamos vestirla hoy? [...] combinar la 'toillette' de ambas, con el buen gusto que manifiestan en toda ocasión". ${ }^{37} \mathrm{Se}$ reproducen estereotipos desde las instancias tempranas de la educación, pues el destinatario es el público infantil.

\section{Estrategias de distinción}

Es oportuno constatar cómo la firma Luxor, en el afán por dar más notoriedad a los productos, resuelve una apuesta alegórica para uno de sus avisos tomando ciertas cualidades de una pintura de trascendencia internacional como Madame Récamier. Si bien las obras plantean diferencias implícitas, se hará foco en los aspectos semánticos.

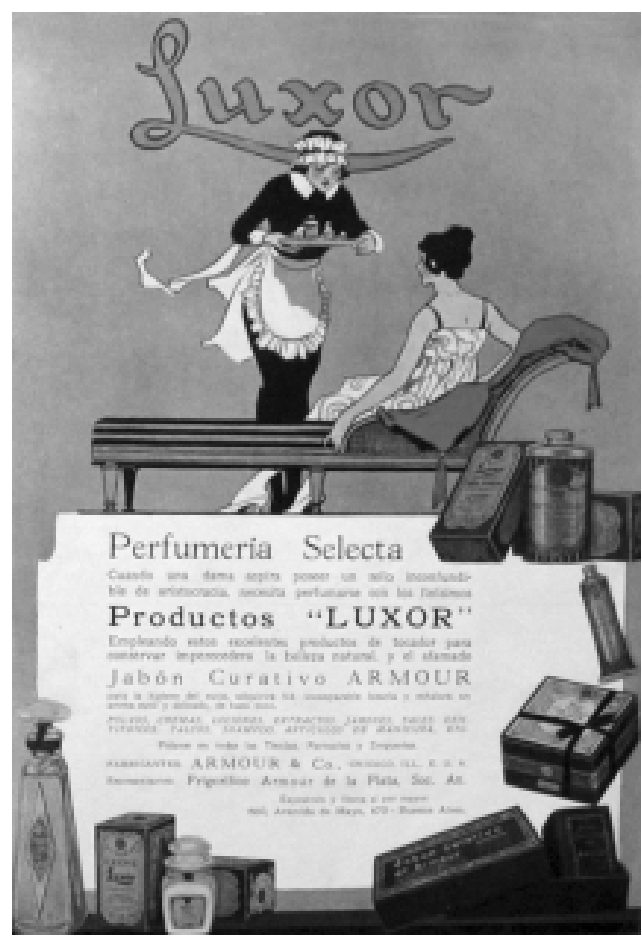

Imagen 4: Plus Ultra, jul. 1919. Jacques-Louis DAVID, 1800. 
${ }^{38}$ Plus Ultra, nov. 1921.

${ }^{39}$ Plus Ultra, nov. 1921
La pintura retrata a Juliette Récamier, esposa de un banquero parisino hacia los inicios del siglo XIX. En relación con su apariencia, viste un chemise de color claro, el cabello recogido y bucles como adopción de los referentes estéticos griegos y romanos, reelaborados por la moda Imperio. Fue una mujer destacada en su tiempo, admirada por su belleza, y símbolo del ascenso social que obtenían ciertos grupos en la coyuntura europea. La pintura era más que un retrato femenino, operaba como representación de un paradigma.

En el caso del aviso publicitario, la protagonista está recostada sobre un diván, sosteniendo una pose de moderación que, junto al corte del atavío y el peinado, guardan cierta analogía con los de Mme. Récamier. El triclinio delata con énfasis la alusión, la presencia del diseño neoclásico remite al modelo histórico. Lo que varía es la resolución de los pies. Si en la pintura la retratada está descalza, condición que provocó controversias, en el aviso el ilustrador apuesta por medias y calzado de taco, una imagen más conveniente para emular en el contexto donde circularía la revista. En la ilustración no se trataría de dar a conocer una tendencia moderna, sino de transmitir una impresión selecta, tomando unidades simbólicas de una pintura consagrada en su tiempo, y que aún lo sigue siendo. Así, los atributos estilísticos evocados coincidirían con las promesas que los directivos de la marca gestionaban para comunicar que los productos participaban en la elaboración de ese ideal y contribuían directamente a su alcance.

El concepto es retomado en otros avisos de cosméticos, entre ellos el del líquido para el cutis Récamier. ${ }^{38}$ En este caso, se presenta una reproducción dibujada de la pintura de Jacques-Louis David, y se señala que el secreto de su belleza estaría al alcance de las lectoras gracias a que el Instituto Récamier había obtenido la fórmula. Es de destacar que se trata de difundir un producto y, conjuntamente, de dar a conocer una institución para el embellecimiento: "demostraciones y aplicaciones se hacen gratuitamente a las damas compradoras de uno o más frascos en el lujoso Instituto Recamier. Atendido por señoritas." ${ }^{39}$

Sobre la escena superior, se divisan figuras masculinas del lado izquierdo y figuras femeninas del derecho, quienes están en posición de reverencia ante uno de los dos varones, que parece ser Napoleón Bonaparte. Los indicios están dados por el monograma emplazado en el ángulo derecho inferior y por los rasgos indumentarios del boceto, coincidentes tipológicamente con evocaciones del personaje. En el fondo, se vislumbra parte de un edificio rodeado de vegetación, un estanque con una figura escultórica y se tiene la sensación, a pesar de su gran síntesis, de estar frente al Palacio de Versalles. 


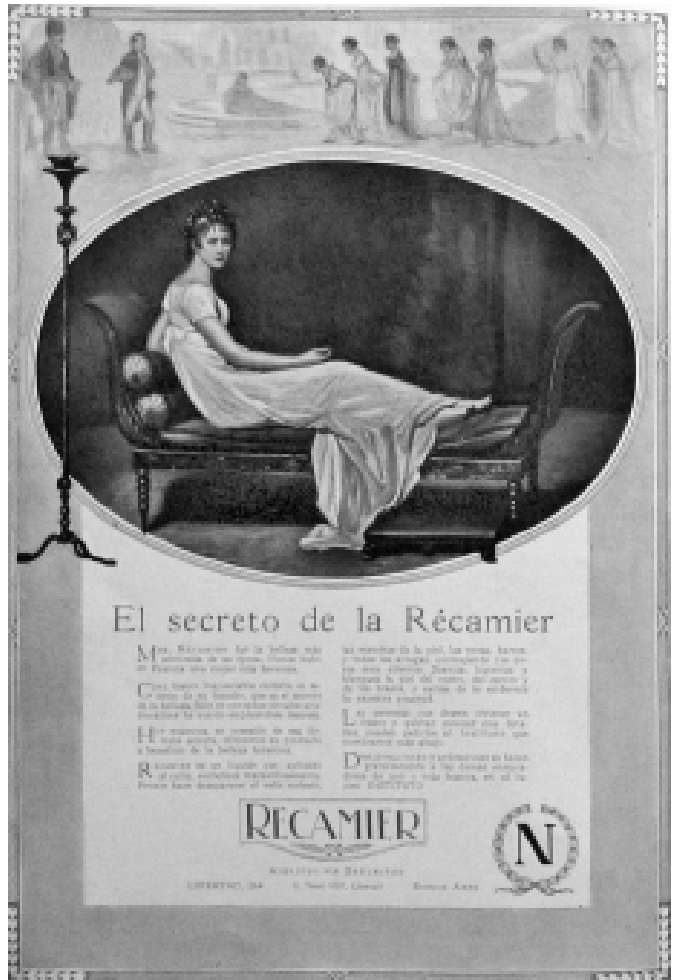

Imagen 5: Plus Ultra, nov. 1921.

Los mensajes de los avisos de la Imagen 4 e Imagen 5 resultan sugestivos en algunas cuestiones. Por un lado, es muy probable que la aparición de Napoleón junto a Mme. haya sido una táctica del ilustrador para aliar dos personajes encumbrados, aunque con una relación poco cordial, en busca de transferir excelencia y sofisticación a los servicios anunciados. Por otro lado, la pintura designa directamente a Francia, y para las argentinas este país era el origen del buen gusto en las modas. Además, la apariencia femenina deseada en tiempos de Récamier se inspiraba en la antigüedad clásica; por lo tanto, y como se dijo, ella no sólo operaba como referente en sí misma, sino que, en su composición intrínseca, vehiculaba un modelo ideal, la joven estaba investida por signos de lo femenino largamente valorizados. Este puede ser uno de los motivos por los que persiste su atractivo como emblema calificado para relacionarse con los productos de tocador.

Es inevitable pensar que el reconocimiento de los sentidos metafóricos dependía de la conexión que las lectoras pudieran establecer con estas figuras y con los significados 
que se insinuaban. Es muy probable que para quienes se mantuvieran distantes a las expresiones culturales analizadas, la proyección de las alegorías haya pasado desapercibida, entonces, el poder de lo visual propendía la emulación de comportamientos exclusivos.

\section{Algunas reflexiones}

Entendiendo que los imaginarios en torno al cuerpo no pueden deslindarse de su traducción en los planos verbal y visual, los cruces de imágenes y prácticas genéricas allanaron, de una forma inclusiva, algunas de las constantes y tensiones en las modalidades de imposición simbólica. Se ha visto cómo se condicionaba, desde las maniobras de factura gráfica, el perfil de las mujeres que se interesaban por el cuidado de su apariencia, apelando a un conjunto autosuficiente y enclasante de variables. Se tendió a enlazar convenciones culturales, con los lugares de pertenencia social y genérica; partiendo de premisas explícitas, quedaba claro que lo virgen debía ceder paso a lo acicalado. Las firmas comerciales abastecieron artefactos para garantizar la conquista, y los productores de mensaje anunciaron los móviles pergeñando escenarios cautivantes. En ese pasaje se instituyeron los alcances de asociar la belleza como uno de los móviles indiscutibles de lo femenino, pero, a su vez, como una ventaja privativa, la capacidad de distinción era mediada por la agencia de exclusiones interpersonales.

El lenguaje iconográfico contribuyó con el de la palabra para hacer trascender la emulación de estas categorías, poniendo en diálogo expresiones de la cultura material e intangible. A través de juegos de analogías y metáforas se alentaron los gustos y consumos selectivos como vías para la legitimación y ratificación de las conductas. Se suministraron cualidades reconocibles y con grados de referencialidad en los personajes a través de la articulación de indicadores trasladados en la fisonomía, y se diseñaron los móviles de consumo que le venían por conveniencia. Ellos acababan enraizando y codificándose en la representación de modelos que satisfacían ampliamente la sensibilidad por la apariencia de una mujer con "calidad de dama". No se trató de una relación aleatoria, sino de una interpretación del aspecto en conjunto del cuerpo en actuación para apuntalar estereotipos altamente valorizados. El montaje de un escenario perfeccionado se convirtió en pretexto para elaborar argumentos de carácter imperativo, también en la visualidad. En el instante captado por el dibujo estaban todos los gestos deseados, y las combinaciones de atributos anhelados eran voluntarias: las modalidades de interacción de los personajes, la mano tomando el producto, el rostro mirándose al espejo. 
En síntesis, se ha podido verificar que la decisión de examinar una imagen como entrada visual a lo social implica para el investigador/a rediseñar un camino que trasciende lo conocido y supera lo estanco. Manifiesta hallar un umbral de análisis versátil, porque el significado de lo representado no se paraliza en el tiempo de su agencia, ni se vuelve obsoleto o trivial. Todo lo contrario, como se dijo, subsiste en las presencias latentes activadas cada vez que se observa la imagen, y esto permite subvertir un significado heredado o inducir aspectos todavía incógnitos. Las imágenes presentadas han sido un pretexto para poner de manifiesto su capacidad por revelar enfoques del pasado. En sí mismas sirvieron como puente en la comunicación de un sistema interpretativo de la visualidad. La búsqueda: el aporte de sentidos vigentes para interpretar las relaciones trazadas entre mujeres y varones en los momentos disímiles de su-nuestra existencia.

\section{Bibliografía}

AMOROS, Celia. La gran diferencia y sus pequeñas consecuencias. Para las luchas de las mujeres. Madrid: Ediciones Cátedra, 2005.

ARFUCH, Leonor. "Una mujer es una mujer. Notas para una semiótica de lo femenino en los medios." Revista Mora, n. 2, p. 112-124, 1996.

ARIZA, Julia. "Bellezas argentinas y femmes de lettres. Representaciones de la mujer en la revista llustrada Plus Ultra (1916-1930)." In: GENE, Marcela, MALOSETTI COSTA, Laura (Comp.) Impresiones porteñas. Imagen y palabra en la historia cultural de Buenos Aires. Buenos Aires: Edhasa, 2009, p. 81-106.

AVISO Brissac. Caras y Caretas, Buenos Aires, año XXIII, $\mathrm{n}$. 1112,24 ene. 1920.

AVISO Brissac. Caras y Caretas, Buenos Aires, año XXIII, $\mathrm{n}$. 1155, 20 de nov. 1924.

AVISO Luxor. Plus Ultra, Buenos Aires, año IV, n. 39, jul. 1919.

AVISO del Instituto Recamier. Plus Ultra, Buenos Aires, año VI, n. 67, nov. 1921.

AVISO Luxor. Plus Ultra, Buenos Aires, año VI, n. 68, dic. 1921. AVISO Odo-ro-no. Plus Ultra, Buenos Aires, año VIII, n. 83, mar. 1923.

AVISO Tinkal. Caras y Caretas, Buenos Aires, año XXXII, n. 1621, 26 de oct. 1929.

AVISO Williams. El Hogar, Buenos Aires, año XVIII, n. 626, 14 de oct. 1921.

BARRANCOS, Dora. Anarquismo, educación y costumbres en la Argentina de principios de siglo. Buenos Aires: Editorial Contrapunto, 1990.

1054 Estudos Feministas, Florianópolis, 21(3): 1039-1058, setembro-dezembro/2013 
BARRANCOS, Dora; CEPPI, Ricardo. "Sexo-s en el lupanar: un documento fotográfico (circa 1940)." Cadernos Pagu, n. 25, p. 357-390, 2005.

BERGER, John. Modos de ver. Barcelona: Gustavo Gilli, 2000.

BETTERTON, Rosemary. Looking on: Images of femininity in the visual Arts and Media. New York: Pandora, 1987.

BOEHM, Gottfried. "Die Wiederkehr der Bilder." In: Was ist ein Bild? Munich: Fink, 1994, p. 11-38.

BOURDIEU, Pierre. La distinción. Criterio y bases sociales del gusto. Madrid: Taurus, 1991.

BURKE, Peter. Formas de Historia Cultural. Madrid: Alianza Editorial, 1999.

BUTLER, Judith. Gender trouble: feminism and subversión of identity. New York: Routledge, 1988.

COSTA, Joan, MOLES, Abraham. Publicidad y diseño. El nuevo reto de la comunicación. Buenos Aires: Ediciones Infinito, 2005.

CHADWICK, Whitney. Mujer, Arte y Sociedad. Barcelona: Ediciones Destino, 1992.

DE BEAUVOIR, Simone. El segundo sexo. Buenos Aires: Ediciones Siglo XX, 1981 [1949].

DE LAURETIS, Teresa. "La tecnología del género." Revista Mora, n. 2, p. 6-34, 1996.

DIDI-HUBERMAN, George. "Has the Epistemological Transformation Taken Place?" In: ZIMMERMANN, Michael (Ed.). The Art Historian: National Traditions and Institutional Practices. Williamstown MA: Clark Art Institute, 2003, p. 128-143. . Ante el tiempo. Buenos Aires: Adriana Hidalgo Editora, 2005.

Cuando las imágenes toman posición. Madrid: A. Machado Libros, 2008.

EL HOGAR, Buenos Aires, año XIX, n. 717, 13 de jul. 1923.

FANGER, Elsie Mc Phail. "Mujeres (ad)miradas y mujeres que miran." Revista de Estudios de Género. La Ventana, vol. 3, n. 28, p. 191-232, dic. 2008.

GEERTZ, Clifford. La interpretación de las culturas. Buenos Aires: Gedisa, 1987.

GENE, Marcela. Un mundo feliz. Imágenes de los trabajadores en el primer peronismo, 1946-1955. Buenos Aires: FCE/San Andrés, 2005.

GINZBURG, Carlo. Mitos, emblemas e indicios. Barcelona: Gedisa, 1994.

GOFFMAN, Erving. Les moments et leurs hommes. París: Minuit, 1988.

La presentación de la persona en la vida cotidiana. Buenos Aires: Amorruti, 1997.

GUASCH, Anna María. "Los Estudios Visuales. Un estado de la cuestión." Estudios Visuales: Los Estudios Visuales en el siglo XXI, n. 1, p. 8-16, dic. 2003. 
GUMBRECHT, Hans-Ulrich. Production of presence: What Meaning Cannot Convey. Stanford: Stanford University Press, 2004.

HIGONNET, Anne. "Mujeres, imágenes y representaciones." In: DUBY, George, PERROT, Michelle (Dir.). Historia de las mujeres en Occidente. v. 5, Madrid: Taurus, 1993, p. 369-398.

JODELET, Denise. "Imaginaires érotiques de l'hygiène féminine intime." Connexions, n. 87, p. 105-127. 105-127, 2007.

KACZAN, Gisela. "La mancha de la playa. Imágenes de paseantes y bañistas a principios del siglo XX." In:

LA CRIADA perfecta. Caras y Caretas, Buenos Aires, año XVIII, n. 627,21 de oct. 1921 .

LA EXPRESIÓN de los pies. El Hogar, Buenos Aires, año XIX, n. 701, 23 de mar. 1923.

LA MAMÁ de Lolot. El Hogar, Buenos Aires, año XIX, n. 692, 19 ene. 1923.

LAMAS Marta (comp.). El género. La construcción cultural de la diferencia sexual. México: Miguel Ángel Porrúa/UNAMPUEG, 1996. 2002.

Cuerpo: Diferencia sexual y género. México: Taurus,

LA PREGUNTA de Titina, ¿qué vestido me pongo? El Hogar, Buenos Aires, año XIX, n. 699, 9 de mar. 1923.

LAS QUE NOS SIRVEN. PBT, Buenos Aires, año II, N 18, 21 de ene. 1905.

LE BRETON, David. La sociología del cuerpo. Buenos Aires: Nueva Visión, 2002.

LE GOFF, Jacques, CHARTIER, Roger, REVEL, Jacques (Dirs.). La nueva historia. Bilbao: Mensajero, 1988.

LEVI, Giovanni. Sobre microhistoria. Buenos Aires: Biblos, 1993.

LOBATO, Mirta (comp.). Cuando las mujeres reinaban: belleza, virtud y poder en la Argentina del siglo $X X$, Buenos Aires: Editorial Biblos, 2005.

Historia de las trabajadoras en la Argentina (18691960). Buenos Aires: Edhasa, 2007.

MALOSETI COSTA, Laura, GENE, Marcela (comp.). Impresiones porteñas. Imagen y palabra en la historia cultural de Buenos Aires. Buenos Aires: Edhasa, 2009.

MAYAYO, Patricia. Historias de mujeres, historias del arte. Madrid: Ensayos Arte Cátedra, 2003.

MELOT, Michel. Breve historia de la imagen. Madrid: Editorial Siruela, 2010.

MIRZOEFF, Nicholas. Una introducción a la cultura visual. Barcelona: Paidós, 2003.

MOXEY, Keith. "Los estudios visuales y el giro icónico." Estudios Visuales: Ensayo, teoría y crítica de la cultura visual y el arte contemporáneo. n. 6, p. 8-27, enero 2009.

NARI, Marcela. "De la maldición al derecho. Notas sobre las mujeres en el mercado de trabajo. Buenos Aires, 1890- 
1940." En: AAW Temas de mujeres- Perspectivas de género. Tucumán: CEHIM-UNT, 1998.

NEWMAN, Kathleen. "Modernization of feminity: Argentina (1916-1926)." In: AA. W: Women, Culture and Politics in Latin America. Seminar of feminism and culture in Latin America. Los Angeles: University of California Press, 1990, p. 74-88.

NUESTRO JUGUETE de la semana. La Mucama. El Hogar, Buenos Aires, año XIX, n. 722, 17 ago. 1923.

La Esfera, Madrid, año I, n. 31, 1 ago. 1914.

POLLOCK, Griselda. Vision and Difference: Femininity and the Histories of Art. London: Routledge, 1988.

QUEIROLO Graciela. "Mujeres que trabajan. Una revisión historiográfica del trabajo femenino en la ciudad de Buenos Aires (1890-1940)." Nuevo Topo, p. 29-50, sep./ oct. 2006.

SAMUEL, Raphael. "El ojo de la historia." Entrepasados, año IX, n. 18-19, p. 145-172, 2000.

SCOTT, Joan. "El género: una categoría útil para el análisis histórico." In: AMELANG, James, NASH Mary (Eds.). Historia y género: las mujeres en la Europa moderna y contemporánea. Valencia: Ediciones Alfons el Magnanim, 1990, p. 37-75.

."La mujer trabajadora en el siglo XIX." En: DUBY, George, PERROT, Michelle (Dir). Historia de las mujeres en Occidente. v. 8, Madrid: Taurus, 1993, p. 99-129.

SIMMEL, George. "La significación estética del rostro." In: SIMMEL, George. El individuo y la libertad. Ensayos

de crítica de la cultura. Barcelona: Península, 2001 [1910], p. 283-292.

"Filosofía de la coquetería." In: SIMMEL, George. De la esencia de la cultura. Buenos Aires: Prometeo, 2007, p. 53-69.

STAFFE, Baronne. Le Cabinet de Toilette. París: Ernest Flammarion Editeur, 1899.

TUBERT, Silvia (ed). Del sexo al género: los equívocos de un concepto. Madrid: Ediciones Cátedra, 2003.

VEBLEN, Thorstein. Teoría de la clase ociosa. Buenos Aires: Hispanoamérica, 2005 [1899].

VERÓN, Eliseo. "El análisis del "Contrato de lectura" un nuevo método para los estudios de posicionamiento de los

soportes de los media". In: Les Medias: Experiences, recherches actuelles, aplications. Paris: IREP, 1985.

. Fragmentos de un tejido. Barcelona: Gedisa, 2004.

VIGARELLO, George. Historia de la belleza. Buenos Aires: Nueva Visión, 2007.

WARBURG, Aby. La Rinascita del Paganesimo Antico. Contributi alla storia della cultura. Florencia: La Nuova Italia, 1966. 
WILLIAMS, Raymond. Cultura. Sociología de la comunicación y del arte. Barcelona: Paidos, 1982.

ZUPPA, Graciela (Edit.). Mar del Plata, otras miradas. Mar del Plata: en proceso de edición.

Representaciones de cuerpos femeninos vestidos: Códigos visuales en los mecanismos de producción de exclusión, emulación y distinción social. Mar del Plata 1900-1930. 2011. Doctorado Interuniversitario de Historia, Universidad Nacional de Mar del Plata, Argentina.

[Recebido em 26 de setembro de 2011 , reapresentado em 8 de novembro de 2012 e aceito para publicação em 5 de dezembro de 2012]

Distinctive Allegories and Social Exclusion Omens in Women's Images (circa 1920) Abstract: The article provides an integrated view between gender studies and visual culture studies. It seeks to interpret the figurations of women in argentine glossy magazines widely available, around 1920, to reflect on the conventions of generic distinctions, behavior emulation, social exclusion representations and articulations between them. It is proposed that the ways of characterizing bodies plays a crucial role so, the appearance, gestures and the evocation of a life style given for the elements of the scene act as iconographic formulas that support the agency of social recognition. Attention is paid to the design and production conditions of discourses, the themes developed, the devices that are used from the languages, and the potential meanings of recognition.

Key Words: Gender studies; Visual culture: Female body images; Distinction mechanisms; Exclusion systems.

1058 Estudos Feministas, Florianópolis, 21 (3): 1039-1058, setembro-dezembro/2013 